\title{
Effects of grazing intensity and the use of veterinary medical products on dung beetle biodiversity in the sub-mountainous landscape of Central Italy
}

\author{
Mattia Tonelli ${ }^{1,2}$, José R. Verdú ${ }^{\text {Corresp., }}{ }^{2}$, Mario E. Zunino ${ }^{1,3}$ \\ 1 Department of Pure and Applied Science, University of Urbino, Urbino, Italy \\ 2 I.U.I. CIBIO, Universidad de Alicante, Alicante, Spain \\ 3 School of Biodiversity, Asti University Centre for Advanced Studies, Asti, Italy \\ Corresponding Author: José R. Verdú \\ Email address: jr.verdu@ua.es
}

Grazing extensification and intensification are among the main problems affecting European grasslands. We analyze the impact of grazing intensity (low and moderate) and the use of veterinary medical products (VMPs) on the dung beetle community in the province of Pesaro-Urbino (Italy). Grazing intensity is a key factor in explaining the diversity of dung beetles. In the case of the alpha diversity component, sites with a low level of grazing activity - related in a previous step to the subsequent abandonment of traditional farming - is characterized by a loss of species richness $(q=0)$ and a reduction in alpha diversity at the levels $q=1$ and $q=2$. In the case of beta diversity, sites with a different grazing intensity show remarkable differences in terms of the composition of their species assemblages. The use of VMPs is another important factor in explaining changes in dung beetle diversity. In sites with a traditional use of VMPs, a significant loss of species richness and biomass is observed, as is a notable effect on beta diversity. In addition, the absence of indicator species in sites with a historical use of VMPs corroborates the hypothesis that these substances have a ubiquitous effect on dung beetles. However, the interaction between grazing activity and VMPs when it comes to explaining changes in dung beetle diversity is less significant (or is not significant) than the main effects (each factor separately) for alpha diversity, biomass and species composition. This may be explained if we consider that both factors affect the various species differently. In other words, the reduction in dung availability affects several larger species more than it does very small species, although this does not imply that the former are more susceptible to injury caused by the ingestion of dung contaminated with VMPs. Finally, in order to prevent negative consequences for dung beetle diversity, we propose the maintenance of a moderate grazing intensity and the rational use of VMPs. It is our view that organic management can prevent excessive extensification while providing an economic stimulus 
to the sector. Simultaneously, it can also prevent the abuse of VMPs. 
1 Effects of grazing intensity and the use of veterinary medical products on dung beetle

2 biodiversity in the sub-mountainous landscape of Central Italy

3

4 Mattia Tonelli ${ }^{1,2}$, José R. Verdú ${ }^{2}$, Mario Zunino ${ }^{1,3}$

5

$6{ }^{1}$ Department of Pure and Applied Science (DiSPeA; previously DiSTeVA), University of

7 Urbino "Carlo Bo", 61029 Urbino (PU), Italy

$8 \quad 2$ I.U.I. CIBIO, Universidad de Alicante, San Vicente del Raspeig, 03069 Alicante, Spain

$9 \quad{ }^{3}$ School of Biodiversity, Asti University Centre for Advanced Studies, Asti, Italy

\section{Abstract}

Grazing extensification and intensification are among the main problems affecting European grasslands. We analyze the impact of grazing intensity (low and moderate) and the use of veterinary medical products (VMPs) on the dung beetle community in the province of PesaroUrbino (Italy). Grazing intensity is a key factor in explaining the diversity of dung beetles. In the case of the alpha diversity components, sites with a low level of grazing activity - related in a previous step to the subsequent abandonment of traditional farming - is characterized by a loss of species richness $(q=0)$ and a reduction in alpha diversity at the levels $q=1$ and $q=2$. In the case of beta diversity, sites with a different grazing intensity show remarkable differences in terms of the composition of their species assemblages. The use of VMPs is another important factor in explaining changes in dung beetle diversity. In sites with a traditional use of VMPs, a significant loss of species richness and biomass is observed, as is a notable effect on beta 
23 diversity. In addition, the absence of indicator species in sites with a historical use of VMPs

24 corroborates the hypothesis that these substances have an ubiquitous effect on dung beetles.

However, the interaction between grazing activity and VMPs when it comes to explaining changes in dung beetle diversity is less significant (or is not significant) than the main effects (each factor separately) for alpha diversity, biomass and species composition. This may be explained if we consider that both factors affect the various species differently. In other words, the reduction in dung availability affects several larger species more than it does very small species, although this does not imply that the former are more susceptible to injury caused by the ingestion of dung contaminated with VMPs.

Finally, in order to prevent negative consequences for dung beetle diversity, we propose the maintenance of a moderate grazing intensity and the rational use of VMPs. It is our view that organic management can prevent excessive extensification while providing an economic stimulus to the sector. Simultaneously, it can also prevent the abuse of VMPs.

\section{Keywords}

Livestock management, traditional grazing, organic farming, ivermectin, Scarabaeidae

\section{Introduction}

Land use changes play a pivotal role in the loss of biodiversity (Sala et al., 2000). In the Mediterranean basin, starting about 10,000 years ago, the human population modified the landscape for agriculture and livestock grazing purposes (Blondel, 2006). Passing through the different stages that have characterized each era (Vos and Meekes, 1999), the basin has developed a complex "cultural landscape" (cfr. Farina, 2000) that enables a large number of 
46 species to be maintained there (Myers et al., 2000). Semi-natural grasslands are one of the

47 keystone habitats of this landscape. They were developed and managed by man (Blondel et al., 48 2010) using extensive livestock grazing that prevented the homogenization of the landscape 49 (Perevolotsky and Seligman, 1998; Diacon-Bolli et al., 2012). This grazing also provides an 50 energy input to the system through the cattle dung that was previously produced by wild 51 herbivores.

52 In these semi-natural grasslands, dung beetles are among the most important groups within 53 the dung fauna (Hanski and Cambefort, 1991). Their bionomics involves them, directly and 54 indirectly, in various ecological processes such as: nutrient cycles, vegetation development, secondary seed dispersion, and parasite control (Halffter and Matthews, 1999; Nichols et al., 56 2008). Dung beetles fulfil all the characteristics of an ideal bioindicator taxon (Spector, 2006,

57 Halffter and Favila, 1993), and have been used in a great number of studies on: habitat

58 disturbance or conversion (Braga et al., 2013; Halffter and Arellano, 2002; McGeoch et al.,

59 2002); the natural environmental gradient (Jay-Robert et al., 1997; Romero-Alcaraz and Ávila,

60 2000); and the vegetation and landscape structure (Numa et al., 2009; Verdú et al., 2011).

61 In the last few decades, extensive livestock management has undergone a rapid process of 62 modification (Stoate et al., 2009). Italy has seen the progressive abandonment of traditional 63 extensive grazing systems in favour of more intensive versions. Furthermore, from 1982 to 2010 , 64 Italian fields lost $20 \%$ of their heads of cattle (cows, sheep and horses), while the livestock of 65 farms fell by about $71 \%$. Nevertheless, the number of horses and sheep rose in the same period 66 in valley areas (more than 13\%) and hills (more than $12 \%$ ), but fell by about $24 \%$ in mountain

67 regions (ISTAT, 2010). Moreover, the number cow herds across the country has decreased by 68 about $35 \%$ in the last 28 years, with $70 \%$ of cows concentrated in the north of Italy in 2010. 
69 Indeed, in this part of the country, the number of cow heads/farm increased from 48 to 64

70

71

72

73

74

75

76

77 between 2000 and 2010 (ISTAT, 2010; Sturaro et al., 2012). This has led to a situation where marginal areas are abandoned, but more productive locations can suffer from overgrazing. Another relevant factor related to intensification is the use/abuse of veterinary medical products (VMPs). These substances are widely utilized, with 194 tons of antiparasitic substances produced in the European Union in 2004 (Kools et al., 2008). VMP molecules such as ivermectin are poorly metabolized by cattle (McKellar and Gokbulut, 2012) and are voided as unchanged residues in faeces (Floate et al., 2005; Lumaret et al., 1993). These residues have been demonstrated to have negative sub-lethal effects and ultimate lethal consequences on non-target dung fauna and, particularly, dung beetles (Verdú et al., 2015; Wardhaugh et al., 2001).

These three factors, i.e. grazing abandonment and intensification and VMP use, have been demonstrated to have negative effects on dung beetle biodiversity. Some studies have focused on the effects on dung beetles of grazing abandonment (Jay-Robert et al., 2008; Verdú et al., 2000; Carpaneto et al., 2005), overgrazing (Negro et al., 2011) and VMP use (for a review see: Beynon, 2012; Lumaret and Errouissi, 2002; Wall and Baynon, 2012; Jacobs and Scholtz, 2015).

When it comes to the impact of VMPs on dung beetles, however, the majority of research has been carried out in the laboratory, with the focus on the effects on a single or just a few species (Verdú et al., 2015; Cruz-Rosales et al., 2012; Hempel et al., 2006; Wardhaugh and RodriguezMenendez, 1988). Nevertheless, it is important to evaluate the impact of different grazing intensities in order to determine the optimum level for dung beetle conservation. This step is necessary because, increasingly, grazing activities are not being completely abandoned, but are instead suffering an ongoing process of extensification (sensu EUROSTAT:

http://ec.europa.eu/eurostat/statistics-explained/index.php/Glossary:Extensification). 
92 Furthermore, pollutants (i.e. VMPs) may interact with "natural stressors" (i.e. the quantity of the 93 trophic resource), producing synergistic or antagonistic effects (Folt et al., 1999; Laskowski et

94 al., 2010). To our knowledge, no studies have evaluated the potential impact of the possible 95 interaction of these two factors on dung beetle diversity.

96 The aim of this study was to analyze the effects of grazing intensity and the use of VMPs on

97 dung beetle diversity in the sub-mountainous landscape of Central Italy. Comparing areas with

98 different grazing intensities (low and moderate) and those with a historical use or non-use of

99 VMPs (used as a proxy of intensification), we attempt to answer the following four questions: A)

100 what is the effect of grazing intensity and VMP use on: dung beetle alpha diversity at different

101 Hill numbers or levels ( $q=0, q=1$, and $q=2$ ), abundance and biomass? B) What is the possible

102 interaction between these factors with respect to dung beetle diversity? C) Are there any

103 indicator species for a particular form of treatment? D) What are the effects on the composition

104 of dung beetle assemblages (beta diversity)? Our hypothesis is that a low level of grazing

105 intensity and the use of VMPs have negative effects on dung beetle biodiversity, resulting in

106 changes in alpha and beta diversity and biomass, and favouring the presence of some species that

107 may act as indicators of a particular form of pasture management. Moreover, we hypothesize that

108 the effects of low grazing intensity and VMP use are worse in combination than alone.

110 Materials and Methods

\section{Study area and experimental design}

112 The study was carried in the sub-mountainous area of the Pesaro-Urbino province in the Marche

113 region, Italy. The provincial climate falls into the temperate Köppen categories (Cfa and $\mathrm{Cfb}$ ).

114 The average annual temperature is around $12{ }^{\circ} \mathrm{C}$, with a minimum average of around $3.5^{\circ} \mathrm{C}$ in 
115 winter and a maximum average of $21^{\circ} \mathrm{C}$ in summer. Average annual precipitation is around 930

$116 \mathrm{~mm}$, with two dry periods, one in summer and another in winter (www.pesarourbinometeo.it).

117 The soil is calcareous.

118 To evaluate the effects of grazing intensity and VMP use, we designed a $2 \times 2$ full factorial

119 design with three replications for each treatment. We identified different areas with: a VMP-free,

120 low grazing intensity; a VMP-free, moderate grazing intensity; a VMP-use, low grazing

121 intensity; and a VMP-use, moderate grazing intensity.

122 A) 'Low grazing, VMP-free’ areas - LGECO - (Pietralata pastures; 4339’33.64'’N;

$\left.12312^{\circ} 42^{\prime} 27.65^{\prime \prime} \mathrm{E}\right)$. These secondary grasslands, located between 750 and $900 \mathrm{~m}$ a.s.l., are

124 represented by the Brizo mediae-Brometum erecti and Festuco circummediterraneae-

125 Arrhenatheretum elatioris associations. These grasslands are mainly used by horses that were

126 abandoned and have reverted to a wild state. The grazing intensity of these pastures is around 0.7

127 units of livestock/ha. The most common wood species are: Fraxinus ornus L., Ostrya

128 carpinifolia Scop., Quercus ilex L., Quercus pubescens Willd., Acer opalus (Miller), Pinus nigra

129 J.F. Arnold, Crataegus monogyna Jacq., Juniperus oxycedrus L., Lonicera etrusca G. Santi,

130 Spartium junceum L., and Rosa canina L.

131 B) 'Moderate grazing, VMP-free' areas - MGECO - (Montebello pastures; 4343'13. 83' 'N;

$\left.13212^{\circ} 45^{\prime} 19.98^{\prime \prime} \mathrm{E}\right)$. These grasslands are located between 500 and $600 \mathrm{~m}$ a.s.l. within the Gino®

133 Girolomoni Cooperativa Agricola. The pastures are used by cows according to organic farming

134 rules with grazing rotation. The grazing intensity is about 1.5 units of livestock/ha. The

135 herbaceous association falls within the Brizo mediae-Brometum erecti group. The spontaneous

136 arboreal vegetation is prevalently comprised of Quercus pubescens, Quercus cerris L., Quercus 
137 petraea (Matt.) Liebl., Carpinus betulus L., Ostrya carpinifolia, Fraxinus ornus L., Acer opalus, 138 Quercus ilex, Sorbus domestica L., Corylus avellana L. and Fagus sylvatica L.

C) 'Moderate grazing with VMPs' areas - MGVMP - (Catria pastures; 4330’23.39’’N;

12³9’22.39’'E). These grasslands are used by cows and horses and have a historical grazing

tradition. The farmers there highlighted that VMPs have long been used and this convention continues to today. The unit of livestock/ha is about 1.5 and there is no sign of overgrazing. These pastures are referred to the association Brizo mediae-Brometum erecti, where the most

144 abundant species are Bromus erectus Huds., Briza media L., Filipendula vulgaris Moench, 145 Cyanus triumfettii (All.) Dostál ex Á.Löve, Plantago lanceolata subsp. lanceolata (Mert. \& Koch), Luzula campestris (L.) DC., Scorzoneroides cichoriacea (Ten.) Greuter, Cynosurus cristatus L., Anthoxanthum odoratum L. and Carex caryophyllea Latourr. The tree species are represented by the Scutellario columnare-Ostryetum carpinifolia association. The sampling sites are located between 800 and $1000 \mathrm{~m}$ a.s.1.

D) 'Low grazing with VMPs' areas - LGVMP - (Nerone pastures; 4332’07.27’’N; $\left.12^{\circ} 33^{\prime} 26.13^{\prime \prime} \mathrm{E}\right)$. These grasslands are grazed by horses that represent a grazing intensity of about 0.5 units of livestock/ha. These sites have been submitted to the historical and intensive use of VMPs from about the 1990s. Today, VMPs are only given to foals and adult animals with evident parasitic stress. The grass associations of these pastures are Asperulo purpureaeBrometum erecti and Brizo mediae-Brometum erecti, with the principal species being: Bromus erectus, Briza media, Filipendula vulgaris, Cyanus triumfettii, Plantago lanceolata subsp. lanceolata, Luzula campestris, Scorzoneroides cichoriacea, Cynosurus cristatus, Anthoxanthum odoratum and Carex caryophyllea. The arboreous species are dominated by the Scutellario 
159 columnare-Ostryetum carpinifolia association. The sampling sites are located between 800 and $1601000 \mathrm{~m}$ a.s.l.

161 The density of wild fauna (i.e. Capreolus capreolus (L., 1758) and Sus scrofa L., 1758) is

162 very similar among all the studied areas (Tonelli, personal observation, 2013).

163 In the areas with VMPs use, the farmers' interviews (Tonelli, unpublished data) highlighted 164 that the VMPs have been use since 1990s until today. The main veterinary formulations that are 165 used are based on Ivermectin and Pyrantel pamoate. The main preventive treatments are 166 administrated in spring and in autumn but the data of application vary between each farmer. 167 Moreover, additional treatments are applied as many times as there are parasitic stress. In the LGVMP areas, VMPs are only given to foals and adult animals with evident parasitic stress, but have a very intense historical use of VMPs.

Dung beetle trapping

172 For each treatment, we selected three sampling sites separated by at least $500 \mathrm{~m}$ to ensure

173 independence among the replicates. In each site, we placed a 50 x $50 \mathrm{~m}$ quadrate with four pitfall 174 traps at the corners; two traps were baited with cow dung (about $500 \mathrm{~cm}^{3}$ ) and two with horse dung (about $500 \mathrm{~cm}^{3}$ ) to maximize differential species attraction (Barbero et al., 1999; Dormont et al., 2004, 2007). The dung used for the trapping was collected from organic farming that was

177 VMP free. We filled the pitfall traps with propylene glycol (50\%) to preserve the dung beetles 178 we collected. The traps were left active for $48 \mathrm{~h}$ in each sampling period. The sampling was 179 repeated about every 15 days from June 2013 to November 2013 and in May and June 2014. We excluded rainy days in order to prevent any interference with the trapping. The total number of traps used was 48 , and we collected a total of 528 samples (4 traps $\mathrm{x} 3$ sampling points $\mathrm{x} 4$ 
182 treatments $\mathrm{x} 11$ sampling periods). The dung beetles were identified to specific level (see

183 Supplemental Information 2, for more details).

184

185 Sampling completeness

186 The inventory completeness was evaluated using a sample coverage analysis (Chao and Jost, 187 2012). This is a measure of sample completeness, and reveals the proportion of the total number 188 of individuals in a community that belong to the species represented in the sample. The sample 189 coverage formula uses information about sample size, singletons and doubletons (Chao and Jost, 190 2012). Measurements were taken using iNext v.1.0 (Hsieh et al., 2013).

192 Alpha diversity

193 Alfa diversity was calculated using the Hill numbers' family diversity (MacArthur, 1965; Hill, 194 1973; Jost, 2006, 2007) (see Supplemental Information 2, for more details). In order to 195 characterize the complete species abundance distribution and provide full information about its 196 diversity, we computed the diversity of the orders 0,1 and 2 for each replication of each 197 treatment for the two factors (grazing intensity and VMP use). We then analyzed these results 198 (each order $q$ separately) using a full factorial generalized linear model in order to evaluate the 199 main effect of the two factors and highlight any interactions. Pairwise comparisons were made 200 using the Tukey post-hoc test. The diversity profile was produced with SpadeR (Chao et al., 201 2015) and the generalized linear model with the Statistica 7.0 package (StatSoft, 2004).

202 
204 We tested the statistical difference in dung beetle total biomass and abundance using a full

205 factorial multivariate generalized linear model with the Statistica 7.0 package (StatSoft, 2004)

206 after log transformation of the dependent variable. Pairwise comparisons were made using the

207 Tukey post-hoc test. The average biomass of each species was calculated using the formula

208 'Biomass $=0.010864 \times$ Length ${ }^{3.316}$ ' suggested by Lobo (1993). Ten individuals of each species

209 (when available) were measured to obtain the average species length (see Supplemental

210 Information 2, for more details). To calculate the total biomass of the dung beetle at each

211 treatment, we multiplied the average biomass of each species by the number of individuals

212 collected and added these numbers together.

214 Beta diversity

215 We analyzed whether grazing intensity and VMP use had any effect on the composition of the

216 dung beetle assemblages. We first calculated an index of multiple community similarity of the

217 two factors (using $q=0,1,2)$ among all the replicates. This produced six similarity matrices ( $3 q$

218 order x 2 factors). Based on these matrices, Non-Metric Multidimensional Scaling (NMDS) were

219 constructed and analyzed using a Permanova test (Anderson, 2001) to evaluate the statistical

220 significance of each factor for the composition of the dung beetle assemblages at each $q$ level.

221 We computed the multiple community similarity of each treatment with a multiple-assemblage

222 abundance-based overlap measure $C_{q N}$ (Chao et al., 2008) (see Supplemental Information 2, for

223 more detail on $C_{q N}$ measures). Similarity matrices were computed using SpadeR (Chao et al.,

224 2015). A Permanova test was performed using the Permanova+ add-on for PRIMER v.7

225 (Anderson et al., 2008; Clarke and Gorley, 2015). Interaction between the factors was also 
226 evaluated. A total of 999 unrestricted permutations of raw data were computed. The $P$ values

227 were calculated using the Bonferroni correction in all cases.

228

229 Indicator species

230 The indicator value method (Dufrêne and Legendre, 1997) was computed for each factor to

231 identify the indicator species of a particular treatment. This method is used to quantify the value,

232 as a bioindicator, of a set of taxa. In relation to a given species, it combines the measurement of

233 the degree of specificity (how much the species tends to be abundant in a particular ecological

234 state) with the measurement of the degree of fidelity (how much the species tends to be present

235 inside a determined ecological state) with respect to a given ecological status (McGeoch et al.,

236 2002; McGeoch and Chown, 1998; Dufrêne and Legendre, 1997). The indicator values range

237 from 0 (no indication) to 100 (perfect indication). Species with significant $(P<0.05)$ IndVal

238 results above $70 \%$ were considered to be indicator species for the given treatment. Species with

239 an intermediate IndVal between $45 \%$ and $70 \%$ were considered to be detector species (McGeoch

240 et al., 2002; Verdú et al., 2011). Indicator species are highly characteristic of a particular

241 ecological state (treatment) and may decline rapidly under other ecological conditions up to the

242 point of disappearance. Detector species have a different degree of preference for different

243 ecological states, and relative changes in their abundance across states may be indicative of the

244 direction in which change is occurring (McGeoch et al., 2002). The analysis was performed

245 using PC-Ord 5 (McCune and Mefford, 1999).

246

247 Results 
248 A total of 148,668 individuals belonging to 57 species of dung beetle were collected (38

249 Aphodiidae, 16 Scarabaeidae, 3 Geotrupidae). This breaks down into: 122,611 specimens

250 belonging to 42 species for the low grazing treatment (25 Aphodiidae, 15 Scarabaeidae, 2

251 Geotrupidae); 26,057 individuals belonging to 54 species for the moderate grazing treatment (35

252 Aphodiidae, 16 Scarabaeidae, 3 Geotrupidae); 128,616 specimens from 53 species for the VMP-

253 free treatment (35 Aphodiidae, 16 Scarabaeidae, 2 Geotrupidae); and 20,052 individuals

254 belonging to 41 species for the VMP-use condition (24 Aphodiidae, 14 Scarabaeidae, 3

255 Geotrupidae) (Supplemental Information 1).

256 The sample coverage estimator revealed that our inventories were $99 \%$ complete for each

257 treatment (Supplemental Information 1). This indicates that only 1\% of the individuals in a

258 community belong to species not represented in our samples. We can thus consider our samples

259 to be complete, and we have utilized empirical data for the diversity analysis and comparisons.

261 Alpha diversity

262 Alpha diversity showed a large decrease in the effective number of species as the $q$ order

263 increased, indicating a high degree of dominance in the studied assemblages. There are

264 significant differences in alpha diversity due to the grazing intensity for all $q$ order $\left({ }^{0} D: F_{[1,8]}=\right.$

265 62.227, $\left.P<0.0001 ;{ }^{1} D: F_{[1,8]}=48.602, P<0.0005 ;{ }^{2} D: F_{[1,8]}=34.131, P<0.0005\right)$, with

266 Moderate grazing that have higher equivalent number of species (post-hoc Tukey test ${ }^{0} D: P<$

$\left.2670.0005 ;{ }^{1} D: P<0.0005 ;{ }^{2} D: P<0.001\right)$ (Figure 1).

268 For VMP use factor significant difference exist only for ${ }^{0} D\left(F_{[1,8]}=242.23, P<0.00001\right)$

269 whereas no significant difference exist for ${ }^{1} D\left(\mathrm{~F}_{[1,8]}=0.062, P=0.81\right)$ and ${ }^{2} D\left(F_{[1,8]}=0.041, P\right.$

$270=0.85$ ). Post-hoc Tukey test show that VMP free areas have more equivalent species that VMP 
271 use areas for ${ }^{0} D(P<0.0005)$ but not for ${ }^{1} D(P=0.81)$ and ${ }^{2} D(P=0.85)$. A small significant

272 interaction between the two factors was identified only for ${ }^{0} D\left(F_{[1,8]}=5.5, P=0.047\right)$, with post-

273 hoc Tukey test that show significant difference between all experimental groups, with the

274 MGECO areas having 1.11 equivalent species more than the LGECO sites, 1.34 more than

275 MGVMP areas and 1.86 more than the LGVMP sites. Sites with LGECO had 1.21 equivalent

276 species more than the MGVMP areas and 1.66 more than the LGVMP sites. The areas with

277 MGVMP had 1.38 equivalent species more than LGVMP sites.

278 No significant interaction between the two factors exists for ${ }^{1} D\left(F_{[1,8]}=1.82, P=0.214\right)$ and

$279{ }^{2} D\left(F_{[1,8]}=0.86, P=0.381\right)$, with post-hoc Tukey test that showed statistical differences only

280 between MGECO areas and LGVMP and LGECO areas, whereas MGVMP had significantly

281 more equivalent species than those of LGVMP and LGECO areas.

282

283 Indicator values of species

284 The IndVal analysis (Table 1) for the grazing intensity factor revealed 10 indicator species:

285 three for the low grazing treatment and seven for the moderate grazing treatment. For the VMP-

286 use factor, 14 indicator species were identified, all with respect to the VMP-free treatment. Two

287 VMP-free indicator species were also indicator species of some treatments for the grazing

288 intensity factor: Chilothorax conspurcatus (L., 1758) is an indicator of the VMP-free and low

289 grazing sites, and Onthophagus taurus (Schreber, 1759) of the VMP-free and moderate grazing 290 treatments.

291

292 Biomass and abundance of dung beetles 
Significant differences in dung beetle biomass and abundance were obtained for the grazing

294

295

296

297

298

299

300

301

302

303

304

305

306

307

308

309

310

311

\section{Discussion}

313

314

315

\section{Beta diversity}

intensity (Wilks's lambda $\left.=0.138 ; F_{[2,7]}=21.87 ; P<0.01\right)$ and use of VMPs factors (Wilks's lambda $\left.=0.17 ; F_{[2,7]}=17.34 ; P<0.05\right)$ (Figure 2). However, no differences were found in their interactions (Wilks's lambda $=0.28 ; F_{[2,7]}=9.13 ; P=0.09$ ). The post-hoc Tukey test showed that the LGECO treatment had a higher dung beetle biomass and abundance than the LGVMP, MGECO and MGVMP treatments, whereas the MGECO treatment had more biomass than the LGVMP treatment.

Multiple-assemblage abundance-based similarity measures $\left(C_{q} N\right)$ showed a clear aggrupation between sites characterised by both factors studied. For each $q$ level, Non-Metric Multidimensional Scaling (NMDS) plots represent a clear ordination of sites based on grazing activity and VMP use (Figure 3). The Permanova test showed significant differences in beta diversity for the grazing intensity factor at each $q$ order of similarity matrix (Table 2). For the VMP-use factor, the Permanova test showed a significant compositional impact only for $q=0$, whereas it was not significant when species abundance was taken into account, i.e. for $q=1$ and $q$ $=2$. Furthermore, the interaction between the two factors was significant only for the similarity matrix of order $q=0$, but was not significant for $q=1$ and $q=2$ (Table 2).

Grazing intensity effects on dung beetle diversity

Our results support the hypothesis that a low grazing intensity have a negative effect on dung beetle diversity. Total domestic grazing abandonment is a recognised negative factor for dung 
316 beetle conservation (Jay-Robert et al., 2008; Verdú et al., 2000). However, our results

317 highlighted that even a simple reduction in grazing intensity implies negative effects on dung

318 beetle community in areas characterised by a long grazing history, such as the Mediterranean

319 Region. Indeed, the areas with a moderate grazing intensity showed more alpha diversity than the

320 low grazing intensity sites. Thus, our results were consistent with those of other studies in

321 different Mediterranean locations. For example, Lobo et al. (2006), in Spain, showed that the

322 quantity of dung in a radius of $2 \mathrm{~km}$ and the presence of a flock are key factors in determining

323 the local variation in dung beetle species richness and abundance. In Southern France, Lumaret

324 et al. (1992) explained that an increase of $260 \%$ in fresh dung availability, five years after a

325 change of pasture management (from sheep to cows), caused an increase in species richness from

32638 to 42 species. In Italy, Carpaneto et al. (2005) showed that after 13 years, the abandonment of

327 the sheep grazing system in the Rome urban area led to a loss of 53\% of the dung beetle species,

328 especially those with a large body size.

329 Furthermore, the decrease in the number of indicator species observed in function of the

330 decrease in grazing intensity supported our hypothesis. We encountered seven and three species

331 with significant IndVal values for the moderate and low grazing areas, respectively. This fact

332 suggest that a reduced quantity of a trophic resource can favour a limited number of species.

333 Moreover, it is interesting to note that in the moderate grazing sites studied, three of the seven

334 indicator species are paracoprids and, among them, one, Copris lunaris (L., 1758), is a large

335 species. During breeding, Copris lunaris may bury about 100-165 g of dung (Klemperer, 1982;

336 Martín-Piera and López-Colón, 2000). Thus, there is a positive relationship between body size

337 and dung mass burial (Doube et al., 1988; Larsen et al., 2005; Slade et al., 2007), which supports 
338 the idea that large paracoprid dung beetle, as C. lunaris, can only to maintain well established

339 populations if the trophic resource is relatively abundant.

340 Our results on the grazing intensity factor can be explained by the species-energy

341 relationship (Gaston, 2000; Wright, 1983; Hawkins et al., 2003), i.e. the lower the level of

342 (trophic) energy available, the smaller the number of species that an area can support (Evans et

343 al., 2005). For example, Tshikae et al. (2013) explicitly tested the species-energy relationship for

344 dung beetles across an arid and trophic resource gradient in Botswana. Their results showed that

345 the species richness, diversity and biomass of the dung beetle diminish with a decrease in

346 available (trophic) energy.

347 However, it is interesting to note that the low grazing areas studied showed greater biomass

348 and abundance. This may be explained by the dominance of two species, Melinopterus consputus

349 (Creutzer, 1799) and Onthophagus medius (Kugelann, 1792). Both species may alter the

350 diversity pattern of this treatment by means of a competitive exclusion (Hardin, 1960). The low

351 quantity of the trophic resource available in this site perturbed the dung beetle community,

352 favouring generalist r-strategic species (such as M. consputus) and highly competitive species

353 such as small tunnellers (e.g. O. medius) (Horgan and Fuentes, 2005). The low grazed sites

354 studied, in fact, showed more biomass but fewer species than the moderately grazed areas. The

355 same results were reported in the Rome urban area (Italy) by Carpaneto et al. (2005), who found

356 a decrease in the number of species and a rise in total biomass, with the dominance of one

357 species of Aphodinae with the same explosive reproductive strategy (i.e. Nimbus johnsoni

358 (Baraud, 1976)).

359 In terms of species composition of assemblages, beta diversity was strongly influenced by the 360 quantity of the trophic resource at all $q$ levels (Table 3); rare and abundant species were 
361 compositionally different between the assemblages obtained in the different grazing intensity

362 treatments. These results implicate that grazing extensification lead to a change in dung beetle

363 composition favouring more opportunistic species. This explanation is corroborated by the

364 presence of three indicators species (Melinopterus consputus, Chilothorax conspurcatus and

365 Sigorus porcus) characteristics of the low grazing areas that share an opportunistic behaviour.

366 Melinopterus consputus and C. conspurcatus are dependent on the dung only during adult stage,

367 whereas during larvae phase are saprophagous, mainly (Verdú J.R. personal observations);

368 Sigorus porcus have a strong attitude to kleptoparasitism during both adult and larval stages

369 (Dellacasa and Dellacasa, 2006).

370 Thus, dung beetles are strongly dependent to dung during their life cycle and our data support

371 the hypothesis that even a simple reduction of its availability may have negative effects on the

372 community. Less trophic resource availability lead to a compositional and structural

373 impoverishment of the community with a loss of large body sizes dung beetles in favour of more

374 opportunistic ones. Then, the fact that Mediterranean pastures suffer a continuous process of

375 extensification, can be a factor of concern for the dung beetle conservation.

376

377 VMPs use effects on dung beetle community

378 Our results supported the hypothesis that the historical use of VMP substances have a negative

379 effect on dung beetle diversity. The negative effect of VMP substances was relevant to all

380 community parameters measured, such as alpha diversity, biomass, abundance, presence of

381 indicator species and beta diversity. It has been documented that VMP-use shows a variety of

382 lethal and sub-lethal effects on non-target fauna depending on the molecule, doses, mode of

383 administration, environmental factors and insect species in question (Lumaret and Errouissi, 
384 2002; Lumaret et al., 2012; Wall and Beynon, 2012; Jacobs and Scholtz, 2015). Many essays

385 show that VMPs negatively affect larval and adult survival of dung beetles, as well as some

386 physiological processes such as reproductive, sensorial and locomotor capacities showing even

387 negative repercussions in the dung decomposition (Wall and Strong, 1987; Lumaret et al., 1993;

388 Wardhaugh et al., 2001; Verdú et al., 2015).

389 Here, we document that VMP-use sites studied showed significantly fewer species and a

390 reduced biomass compared to the VMP-free sites. Our results agree with other studies that have

391 explored the impact of VMPs in the field. For example, in southern Ireland, Hutton and Giller

392 (2003) observed a lower number of species and a reduced abundance of dung beetles in intensive

393 and rough grazing farms compared to organic farms. In South Africa, Krüger and Scholtz (1998)

394 also showed that, under drought conditions, treatment with ivermectin led to a loss of dung

395 beetle species. Beynon et al. (2012b) showed a reduction in dung beetle abundance and biomass

396 in dung treated with ivermectin in the UK.

397 Unlike some studies (Krüger and Scholtz, 1998; Basto-Estrella et al., 2014; Hutton and

398 Giller, 2003), we did not find a significant difference in ${ }^{1} D$ ('common species number') and ${ }^{2} D$

399 ('dominant species number') for the VMP-use factor. Give that macrocyclic lactones as

400 ivermectin acting on a family of ligand-gated chloride channels gated by glutamate, which is

401 shared by all Ecdysozoan (Geary and Moreno, 2012; Puniamoorthy et al., 2014), all dung beetles

402 species should be sensible to ivermectin toxicity. Thus, the consequences on the assemblage

403 structure may be differential based on the abundances of each species in each assemblage. Our

404 data showed that less common species are first in disappearing in sites characterized by VMPs

405 use, which explains the significant reduction in the number of species observed in these sites. At

$406 q=1$ and $q=2$, however, differences are not observed between both treatments, so the reduction 
407 of the populations of the most common and dominant species took place of equitable way, which

408 maintains similar measures of community structure $\left({ }^{1} D\right.$ and $\left.{ }^{2} D\right)$.

409 Accordingly to alpha diversity results, beta diversity was influenced by the use of VMPs only

410 for $q=0$. This means that the two assemblages are different in terms of 'rare' species, whereas

411 the more common and dominant species are not significantly different.

412 Our IndVal results showed how the VMP-use treatments have no indicator species. This

413 means that no species were favoured by the use of these veterinary substances. In other words,

414 the use of VMPs could affect all species and, apparently, no species could be resistant to VMP

415 toxicity. These results agree with the explained above about diversity measures. In contrast, the

416 VMP-free treatment had 14 indicator species.

417 Our results are congruent with those of Puniamoorthy et al. (2014), which show that

418 ivermectin sensitivity is an ancient trait affecting potentially all Ecdysozoan (moulting animals)

419 species. This corroborates the hypothesis that the use of VMPs may have a ubiquitous, negative

420 effect on dung beetle fauna. The fact that no species were found to be indicator species in the

421 areas with VMP-use could be due to the irrational use of these substances throughout the year.

422

423 Grazing intensity and VMPs interactions

424 Interesting results were highlighted by the interactions between the two factors. Contrary to our

425 hypothesis, the interactions terms were less significant, or no more significant, than the main

426 effects (each factor separately) for alpha diversity, biomass and species composition. This could

427 be explained if we consider that both factors affect different forms of each species. In other

428 words, the decrease in dung availability affects several bigger species more than the very small

429 species, but this does not imply that the former are more susceptible to injury caused by the 
430 ingestion of dung contaminated with VMPs. Another explanation can be found in the halving of

431 the sample size during the interaction analyses. This means that interactions between the two

432 factors may have antagonistic effects on dung beetle assemblages, but more studies with greater

433 sample size are needed on this issue.

434

435 Conclusions

436 The present analysis highlighted that the moderate grazing VMP-free treatment seems to be the

437 more appropriate management system for maintaining a higher number of dung beetle species, as

438 well as greater diversity and biomass. These results corroborated the notion that, in a

439 Mediterranean context with a long history of grazing, traditional management techniques with a

440 moderate grazing intensity have a positive effect on dung beetle diversity (Verdú et al., 2000).

441 Furthermore, our results corroborated the hypothesis that both factors - low grazing intensity and

442 VMP-use - have negative effects on dung beetle communities. Even a simple grazing intensity

443 extensification may have negative impact on dung beetle, that is reflected in the compositional

444 and structural impoverishment of the community. Our study strengthens the results about the

445 environmental risk assessment made by Liebig et al. (2010) that concluded that the ivermectin

446 use have an "unacceptable risk" for dung beetle fauna.

447 The results could have an application for sustainable farmland management, highlighting that 448 an incorrect grazing management of the pastures could be a strong effect on dung beetle

449 community (e.g. number of species, biomass, composition), and so in the correct function of

450 ecosystem processes performed by dung beetle as nutrient cycles, vegetation development,

451 secondary seed dispersion, and parasite control (Nichols et al., 2008; Nervo et al., 2014; Beynon 
452 et al., 2012a; Larsen et al., 2005). Then, the loss of dung beetle biodiversity can have a negative

453 impact on various ecosystem processes (Nichols et al., 2008), with harmful effects on pastures.

454 Finally, we suggest that organic farming with a moderate grazing intensity could have a

455 positive effect on dung beetle conservation. This farming management approach may contribute

456 to this by avoiding pasture abandonment, conferring an economic stimulus (Willer and Lernoud,

457 2016) and controlling for the excessive use of VMPs (Hutton and Giller, 2003). Further studies

458 in different biogeographical and bioclimatic regions are, however, needed to assess the impact of

459 the long-term use of VMPs on dung beetles.

460

461

\section{Acknowledgements}

462 Sally-Ann Ross checked the English version of the manuscript.

463

464

\section{References}

Anderson, M.J., 2001. A new method for a non-parametric multivariate analysis of variance. Austral Ecology, 26(1): 32-46.

Anderson, M.J., Gorley, R.N., Clarke, K.R. 2008. PERMANOVA+ for PRIMER: Guide to Software and Statistical Methods: PRIMER-E: Plymouth, UK.

Barbero, E., Palestrini, C., Rolando, A., 1999. Dung beetle conservation: effects of habitat and re source selection (Coleoptera: Scarabaeoidea). Journal of Insect Conservation, 3: 75-84.

Basto-Estrella, G.S., Rodríguez-Vivas, R.I., Delfín-González, Reyes-Novelo, E., 2014. Dung beetle (Coleoptera: Scarabaeinea) diversity and seasonality in response to use of macrocyclic lactones at cattle ranches in the Mexican neotropics. Insect Conservation and

$474 \quad$ Diversity, 7: 73-81. 
475 Beynon, S.A., 2012. Potential environmental consequences of administration of anthelmintics to 476 sheep. Veterinary Parasitology, 189: 113-124.

477 Beynon S.A., Mann, D.J., Slade, E.M., Lewis, O.T., 2012a. Species-rich dung beetle

478 communities buffer ecosystem services in perturbed agro-ecosystems. Journal of Applied Ecology, 49(6): 1365-1372.

480

481

482

483

484

485

486

487

488

489

490

491

492

493

494

495

496

497

Beynon, S.A., Peck, M., Mann D.J., Lewis, O.T., 2012b. Consequences of alternative and conventional endoparasite control in cattle for dung-associated invertebrates and ecosystem functioning. Agriculture, Ecosystem and Environment, 162: 36-44.

Blondel, J., 2006. The 'design' of Mediterranean landscapes: a millennial story of humans and ecological systems during the historic period. Human Ecology, 34(5): 713-729.

Blondel, J., Aronson, J., Bodiou, J.-Y., Boeuf, G., 2010. The Mediterranean Region: Biological Diversity in Space and Time. Second Edition. Oxford University Press Inc., New York.

Braga, R.F., Korasaki, V., Andresen, E., Louzada, J., 2013. Dung beetle community and functions along a habitat-disturbance gradient in the Amazon: a rapid assessment of ecological functions associated to biodiversity. PLoS ONE, 8(2): e57786. doi:10.1371/journal.pone.0057786

Carpaneto, G.M., Mazziotta, A., Piattella, E., 2005. Changes in food resources and conservation of scarab beetles: from sheep to dog dung in a green urban area of Rome (Coleoptera, Scarabaeoidea). Biological Conservation, 123: 547-556.

Chao, A., Jost, L., 2012. Coverage-based rarefaction and extrapolation: standardizing samples by completeness rather than size. Ecology, 93(12): 2533-2547.

Chao, A., Jost, L., Chiang, S.-C., Jiang, Y.-H., 2008. A two-stage probabilistic approach to multiple-assemblage similarity indices. Biometrics, 64: 1178-1186. 
498 Chao, A., Ma, K.H., Hsieh, T.C., 2015. The Online Program SpadeR: Species-richness

499 Prediction and Diversity Estimation in R. Program and User's Guide published at $500 \quad$ http://chao.stat.nthu.edu.tw/blog/software-download/.

501 Clarke, K.R., Gorley, R.N. 2015. PRIMER v7: User Manual/Tutorial, PRIMER-E: Plymouth.

502 Cruz-Rosales, M., Martínez, I.M., López-Collado, J., Vargas-Mendoza, M., González-

503 Hernández, H., Fajersson, P., 2012. Effect of ivermectin on the survival and fecundity of

504 Euoniticellus intermedius (Coleoptera: Scarabaeidae). Revista de Biologia Tropical, 60(1):

$505 \quad 333-345$.

506 Dellacasa, G., Dellacasa, M., 2006. Coleoptera Aphodiidae, Aphodiinae. Fauna d'Italia Vol.

507 XLI, Coleoptera Aphodiidae Aphodiinae. Calderini de Il Sole 24 Ore. Milán. Italia. 484 pp.

508 Diacon-Bolli, J., Dalang, T., Holderegger, R., Bürgi, M., 2012. Heterogeneity fosters

509 biodiversity: linking history and ecology of dry calcareous grasslands. Basic and Applied

$510 \quad$ Ecology, 13: 641-653.

511 Dormont, L., Epinat, G., Lumaret J.-P., 2004. Trophic preferences mediated by olfactory cues in

512 dung beetles colonizing cattle and horse dung. Environmental Entomology, 33(2): 370-377.

513 Dormont, L., Rapior, S., McKey, D.B., Lumaret J.-P., 2007. Influence of dung volatiles on the

514 process of resource selection by coprophagous beetles. Chemoecology, 17: 23-30.

515 Doube, B.M., Giller, P.S., Moola, F., 1988. Dung burial strategies in some South African coprine 516 and onitine dung beetles (Scarabaeidae: Scarabaeinae). Ecological Entomology, 13: 251517261.

518 Dufrêne, M., Legendre, P., 1997. Species assemblages and indicator species: the need for a

519 flexible asymmetrical approach. Ecological Monographs, 67(3): 345-366. 
520 Evans, K.L., Warren, P.H., Gaston, K.J., 2005. Species-energy relationships at the

521 macroecological scale: a review of the mechanisms. Biological Reviews, 80(1): 1-25.

522 Farina, A., 2000. The cultural landscape as a model for the integration of ecology and 523 economics. BioScience, 50(4): 313-320.

524 Floate, K.D., Wardhaugh, K.G., Boxall, A.B.A., Sherratt, T.N., 2005. Fecal residues of 525 veterinary parasiticides: nontarget effects in the pasture environment. Annual Review of 526 Entomology, 50: 153-179.

527 Folt, C.L., Chen, C.Y., Moore, M.V., Burnaford, J., 1999. Synergism and antagonism among 528 multiple stressors. Limnology and Oceanography, 44(3, part 2): 864-877.

529 Gaston, K.J., 2000. Global patterns in biodiversity. Nature, 405: 220-227.

530 Geary, T.G., Moreno, Y., 2012. Macrocyclic lactone anthelmintics: spectrum of activity and 531 mechanism of action. Current Pharmaceutical Biotechnology, 13: 866-872.

532 Halffter, G., Arellano, L., 2002. Response of dung beetle diversity to human-induced changes in 533 a tropical landscape. Biotropica, 34(1): 144-154.

534 Halffter, G., Favila, E., 1993. The Scarabaeinae (Insecta: Coleoptera) an animal group for 535 analyzing, inventorying and monitoring biodiversity in tropical rainforest and modified $536 \quad$ landscapes. Biology International, 27: 15-21.

537 Halffter, G., Matthews, E.G., 1999. The natural history of dung beetles of the subfamily 538 Scarabaeinae. Medical Books, Palermo, 313 pp.

539 Hanski, I., Cambefort, Y., (Eds.) 1991. Dung Beetle Ecology. Princeton University Press, $540 \quad$ Princeton, NJ, $481 \mathrm{pp}$.

541 Hardin, G., 1960. The competitive exclusion principle. Science, 131: 1292-1297. 
542 Hawkins, B.A., Field, R., Cornell, H.V., Currie, D.J., Guegan, J., Kaufman, D.M., Kerr, J.T.,

543 Mittelbach, G.G., Oberdorff, T., O’Brien, E.M., Porter, E.E., Turner J.R.G., 2003. Energy,

544 water, and broad-scale geographic patterns of species richness. Ecology, 84(12): 3105-

$545 \quad 3117$.

546 Hempel, H., Scheffczyk, A., Schallnaß, H.-J., Lumaret, J.-P., Alvinerie, M., Römbke, J., 2006.

547 Toxicity of four veterinary parasiticides on larvae of the dung beetle Aphodius constans in 548 the laboratory. Environmental Toxicology and Chemistry, 25(12): 3155-3163.

549 Hill, M.O. 1973. Diversity and evenness: a unifying notation and its consequences. Ecology, 54:

$550 \quad 427-432$.

551 Horgan, F.G., Fuentes, R.C., 2005. Asymmetrical competition between Neotropical dung beetles 552 and its consequences for assemblage structure. Ecological Entomology, 30: 182-193.

553 Hsieh, T. C., K. H. Ma, and A. Chao. 2013. iNEXT online: interpolation and extrapolation

554 (Version 1.0) [Software]. Available from http://chao.stat.nthu.edu.tw/blog/software555 download/.

556 Hutton, S.A., Giller, P.S., 2003. The effects of the intensification of agriculture on northern

557 temperate dung beetle communities. Journal of Applied Ecology, 40: 994-1007.

558 ISTAT 2010. $6^{\circ}$ Censimento generale dell'agricoltura. ISTAT: Roma.

559 http://censimentoagricoltura.istat.it/Jacobs C.T., Scholtz, C.H., 2015. A review on the 560 effect of macrocyclic lactones on dung-dwelling insects: Toxicity of macrocyclic lactones 561 to dung beetles. Onderstepoort Journal of Veterinary Research, 82(1): Art.\#858, 8 pages. 562 http://dx.doi.org/ 10.4102/ojvr.v82i1.858 
563 Jay-Robert, P., Lobo, J.M., Lumaret, J.-P. 1997. Elevational turnover and species richness

564 variation in European mountain dung beetle assemblages. Arctic, Antarctic, and Alpine

565 Research, 29: 196-205.

566 Jay-Robert, P., Niogret, J., Errouissi, F., Labarussias, M., Paoletti, E., Vázquez Luis, M.,

567 Lumaret, J.-P., 2008. Relative efficiency of extensive grazing vs. wild ungulates

568 management for dung beetle conservation in a heterogeneous landscape from Southern

569 Europe (Scarabaeinae, Aphodiinae, Geotrupinae). Biological Conservation, 141: 2879-

$570 \quad 2887$.

571 Jost, L., 2006. Entropy and diversity. Oikos, 113: 363-375.

572 Jost, L., 2007. Partitioning diversity into independent alpha and beta components. Ecology, 88:

$573 \quad 2427-2439$.

574 Klemperer, H.G., 1982. Parental behavior in Copris lunaris (Coleoptera, Scarabaeidae): care and 575 defense of brood balls and nest. Ecological Entomology, 7: 155-167.

576 Kools, S.A., Moltmann, J.F., Knacker, T., 2008. Estimating the use of veterinary medicines in 577 the European Union. Regulatory Toxicology and Pharmacology, 50: 59-65.

578 Krüger, K., Scholtz, C.H., 1998. Changes in the structure of dung insect communities after 579 ivermectin usage in a grassland ecosystem. I. Impact of ivermectin under drought $580 \quad$ conditions. Acta Oecologica, 19(5): 425-438.

581 Larsen, T., Williams, N., Kremen, C., 2005. Extinction order and altered community structure 582 rapidly disrupt ecosystem functioning. Ecology Letters, 8: 538-547.

583 Laskowski, R., Bednarska, A.J., Kramarz, P.E., Loureiro, S., Scheil, V., Kudlek, J., Holmstrup, 584 M., 2010. Interactions between toxic chemicals and natural environmental factors - A 585 meta-analysis and case studies. Science of the Total Environment, 408: 3763-3774. 
586 Liebig, M., Fernandez, Á.A., Blübaum-Gronau, E., Boxall, A., Brinke, M., Carbonell, G., Egeler,

587 P., Fenner, K., Fernandez, C., Fink, G., Garric, J., Halling-Sørensen, B., Knacker, T.,

588 Krogh, K.A., Küster, A., Löffler, D., Cots, M.Á.P., Pope, L., Prasse, C., Römbke, J.,

589 Rönnefahrt, I., Schneider, M.K., Schweitzer, N., Tarazona, J.V., Ternes, T.A.,

590 Traunspurger, W., Wehrhan, A., Duis, K., 2010. Environmental risk assessment of

591 Ivermectin: a case study. Integrated Environmental Assessment and Management, 6(1):

$592 \quad 567-587$.

593 Lobo, J.M., 1993. Estimation of dung beetle biomass (Coleoptera: Scarabaeoidea). European

$594 \quad$ Journal of Entomology, 90: 235-238.

595 Lobo, J.M., Hortal, J., Cabrero-Sañudo F.J., 2006. Regional and local influence of grazing

596 activity on the diversity of a semi-arid dung beetle community. Diversity and Distribution,

$597 \quad 12: 111-123$.

598 Lumaret, J.-P., Errouissi, F., 2002. Use of anthelmintics in herbivores and evaluation of risks for

599 the non target fauna of pastures. Veterinary Research, 33: 547-562.

600 Lumaret, J.-P., Errouissi, F., Floate, K., Römbke, J., Wardhaugh, K., 2012. A review on the

601 toxicity and non-target effects of macrocyclic lactones in terrestrial and aquatic

602 environments. Current Pharmaceutical Biotechnology, 13: 1004-1060.

603 Lumaret, J.-P., Galante, E., Lumbreras, C., Mena, J., Bertrand, M., Bernal, J.L., Cooper, J.F.,

604 Kadiri, N., Crowe, D., 1993. Field effects of ivermectin residues on dung beetles. Journal

605 of Applied Ecology, 30: 428-436.

606 Lumaret, J.-P., Kadiri, N., Bertrand, M., 1992. Changes in resources: consequences for the

607 dynamics of dung beetle communities. Journal of Applied Ecology, 29: 349-356.

608 MacArthur, R.H., 1965. Patterns of species diversity. Biological Reviews, 40(4): 510-533. 
609 Martín-Piera, F., López-Colón, J.I. 2000. Coleoptera, Scarabaeoidea I. Fauna Ibérica, vol. 14. 610 Ramos, M.A., et al (Eds.). Museo Nacional de Ciencias Naturales. CSIC. Madrid. 528 pp. 611 McCune, B., Mefford M.J., 1999. Multivariate Analysis of Ecological Data, Version 4.0. MjM 612 Software, Gleneden Beach, Oregon, U.S.A.

613 McGeoch, M.A., Chown, S.L., 1998. Scaling up the value of bioindicators. Trends in Ecology $614 \quad$ and Evolution, 13: 46-47.

615 McGeoch, M.A., van Rensburg, B.J., Botes, A., 2002. The verification and application of 616 bioindicators: a case study of dung beetles in a savanna ecosystem. Journal of Applied $617 \quad$ Ecology, 39(4): 661-672.

618 McKellar, Q., Gokbulut, C., 2012. Pharmacokinetic features of the antiparasitic macrocyclic 619 lactones. Current Pharmaceutical Biotechnology, 13: 888-911.

620 Myers, N., Mittermeier, R.A., Mittermeier, C.G., de Fonseca G.A.B., Kent, J., 2000. Biodiversity 621 hotspots for conservation priorities. Nature, 403: 853-858

622 Negro, M., Rolando, A., Palestrini, C., 2011. The impact of overgrazing on dung beetle diversity 623 in the Italian Maritime Alps. Environmental Entomology, 40(5): 1081-1092.

624 Nervo, B., Tocco, C., Caprio, E., Palestrini, C., Rolando, A., 2014. The effects of body mass on 625 dung removal efficiency in dung beetles. PLoS ONE, 9(9): e107699. Doi:

$626 \quad$ 10.1371/journal.pone.0107699

627 Nichols, E., Spector, S., Louzada, J., Larsen, T., Amezquita, S., Favila, M.E., 2008. Ecological 628 functions and ecosystem services provided by Scarabaeinae dung beetles. Biological 629 Conservation, 141(6): 1461-1474. 
630 Numa, C., Verdú, J.R., Sánchez, A., Galante, E., 2009. Effect of landscape structure on the 631 spatial distribution of Mediterranean dung beetle diversity. Diversity and Distributions, $632 \quad 15(3): 489-501$.

633 Perevolotsky, A., Seligman, N.G., 1998. Degradation of Mediterranean rangeland ecosystems by 634 grazing: Inversion of a paradigm. BioScience, 48: 1007-1017.

635 Pesaro Urbino Meteo. Available at: www.pesarourbinometeo.it (accessed 28 January 2016)

636 Puniamoorthy, N., Schäfer, M.A., Römbke, J., Meier, R. and W.U. Blanckenhorn. 2014.

637 Ivermectin sensitivity is an ancient trait affecting all Ecdysozoa but shows phylogenetic $638 \quad$ clustering among sepsid flies. Evolutionary Applications, 7: 548-554.

639 Romero-Alcaraz, E., Ávila, J.M., 2000. Effect of elevation and type of habitat on the abundance 640 and diversity of scarabaeoid dung beetle (Scarabaeoidea) assemblages in a Mediterranean 641 area from southern Iberian peninsula. Zoological Studies, 39(4): 351-359.

642 Sala, O.E., Chapin III, F.S., Armesto, J.J., Berlow, E., Bloomfield, J., Dirzo, R., Huber-Sanwald, 643 E., Huenneke, L.F., Jackson, R.B., Kinzig, A., Leemans, R., Lodge, D.M., Mooney, H.A., 644 Oesterheld, M., Poff, N.L., Sykes, M.T., Walker, B.H., Walker, M., Wall, D.H., 2000. 645 Global biodiversity scenarios for the year 2100. Science, 287: 1770-1774.

646 Slade, E.M., Mann, D.J., Villanueva, J.F., Lewis, O.T., 2007. Experimental evidence for the 647 effects of dung beetle functional group richness and composition on ecosystem function in 648 a tropical forest. Journal of Animal Ecology, 76: 1094-1104.

649 Spector, S., 2006. Scarabaeine dung beetles (Coleoptera: Scarabaeidae: Scarabaeinae): an 650 invertebrate focal taxon for biodiversity research and conservation. The Coleopterists 651 Bulletin, Monograph Number, 5: 71-83. 
652 StatSoft, Inc. (2004). STATISTICA (data analysis software system), version 7.

$653 \quad$ www.statsoft.com.

654 Stoate, C., Báldi, A., Beja, P., Boatman, N.D., Herzon, I., van Doorn, A., de Snoo, G.R., Rakosy,

655 L., Ramwell, C., 2009. Ecological impacts of early $21^{\text {st }}$ century agricultural change in

656 Europe - A review. Journal of Environmental Management, 91: 22-46.

657 Sturaro, E., Cassandro, M., Cozzi, G., 2012. Sustainability of cattle farms in Italy. $20^{\circ}$

658 International Symposium, “Animal Science Days”, Kranjska gora, Slovenia, September 19-

$659 \quad 21,2012$.

660 Tshikae, B.P., Davis, A.L.V., Scholtz, C.H., 2013. Species richness - Energy relationship and

661 dung beetle diversity across an aridity and trophic resource gradient. Acta Oecologica, 13:

$662 \quad 71-82$.

663 Verdú, J.R., Cortez, V., Ortiz, A.J., González-Rodríguez, E., Martinez-Pinna, J., Lumaret, J.-P.,

664 Lobo, J.M., Numa, C., Sánchez-Piñero, F., 2015. Low doses of ivermectin cause sensory

665 and locomotor disorders in dung beetles. Scientific Reports, 5: 13912. doi:

$666 \quad \underline{10.1038 / \operatorname{srep} 13912}$

667 Verdú, J.R., Crespo, M.B., Galante, E., 2000. Conservation strategy of a nature reserve in

668 Mediterranean ecosystems: the effects of protection from grazing on biodiversity.

669 Biodiversity and Conservation, 9: 1707-1721.

670 Verdú, J.R., Numa, C., Hernández-Cuba, O., 2011. The influence of landscape structure on ants

671 and dung beetles diversity in a Mediterranean savanna-Forest ecosystem. Ecological

$672 \quad$ Indicators, 11(3): 831-839.

673 Vos, W., Meekes, H., 1999. Trends in European cultural landscape development: perspectives

674 for a sustainable future. Landscape and Urban Planning, 46: 3-14. 
675 Wall, R., Beynon, S., 2012. Area-wide impact of macrocyclic lactone parasiticides in cattle 676 dung. Medical and Veterinary Entomology, 26: 1-8.

677 Wall, R., Strong, L., 1987. Environmental consequences of treating cattle with the antiparasitic 678 drug ivermectin. Nature, 327: 418-421.

679 Wardhaugh, K.G., Longstaff, B.C., Morton, R., 2001. A comparison of the development and 680 survival of the dung beetle, Onthophagus taurus (Schreb.) when fed on the faeces of cattle 681 treated with pour-on formulations of eprinomectin or moxidectin. Veterinary Parasitology, $68299: 155-168$.

683 Wardhaugh, K.G., Rodriguez-Menendez, H., 1988. The effects of the antiparasitic drug, 684 ivermectin, on the development and survival of the dung-breeding fly, Orthelia cornicina 685 (F.) and the scarabaeine dung beetles, Copris hispanus L., Bubas bubalus (Oliver) and 686 Onitis belial F. Journal of Applied Entomology, 106: 381-389.

687 Willer, H., Lernoud, J., (Eds.) 2016. The world of organic agriculture. Statistics and emerging 688 trends 2016. Research Institute of Organic Agriculture (FiBL), Frick, and IFOAM 689 Organic International, Bonn.

690 Wright, D.H., 1983. Species-energy theory: an extension of species-area theory. Oikos 41: 496691 506. 


\section{Figure 1}

Alpha diversity of dung beetles in sub-mountainous landscapes of Central Italy.

Alpha diversity of dung beetles using Hill numbers for both grazing intensity levels (low and moderate) and Veterinary Medical Products use (VMP use and VMP free). ${ }^{\circ} D$ (blue) correspond to species richness; ${ }^{1} D$ (red) and ${ }^{2} D$ (green) are the alpha diversity indices of $q=$ 1 and $q=2$, respectively. Dots represents mean and bars represent standard errors. Different letters mean significant differences (post-hoc Tukey test $P<0.05$, with Bonferroni correction). 


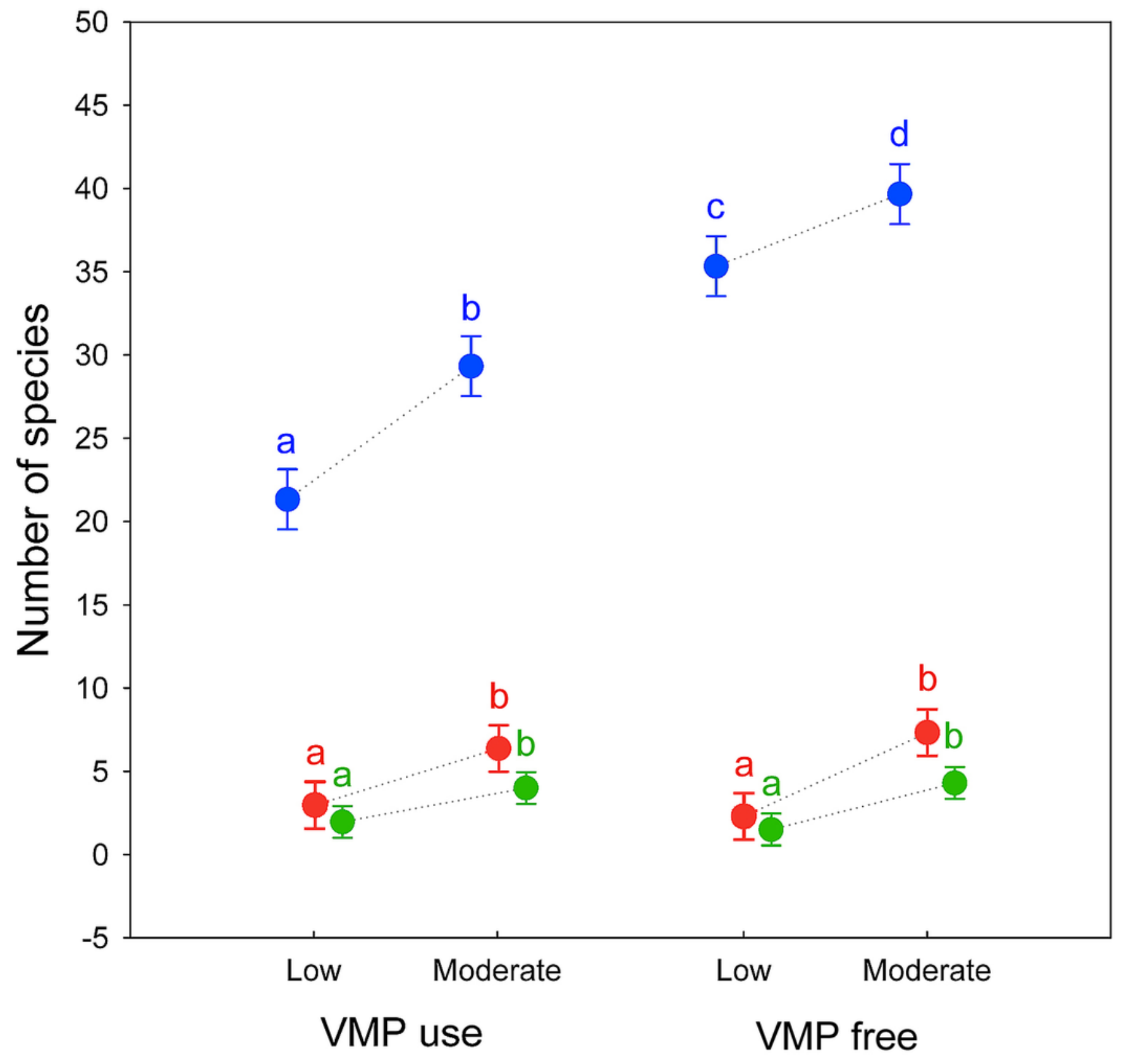




\section{Figure 2}

Dung beetle biomass and abundance in sub-mountainous landscapes of Central Italy.

Dung beetle biomass (blue) and abundance (red) for different grazing intensity levels (low and moderate) and Veterinary Medical Products use (VMP use and VMP free). Dots represents mean and bars represent standard errors. Different letters mean significant differences (post-hoc Tukey test $P<0.05$, with Bonferroni correction). 


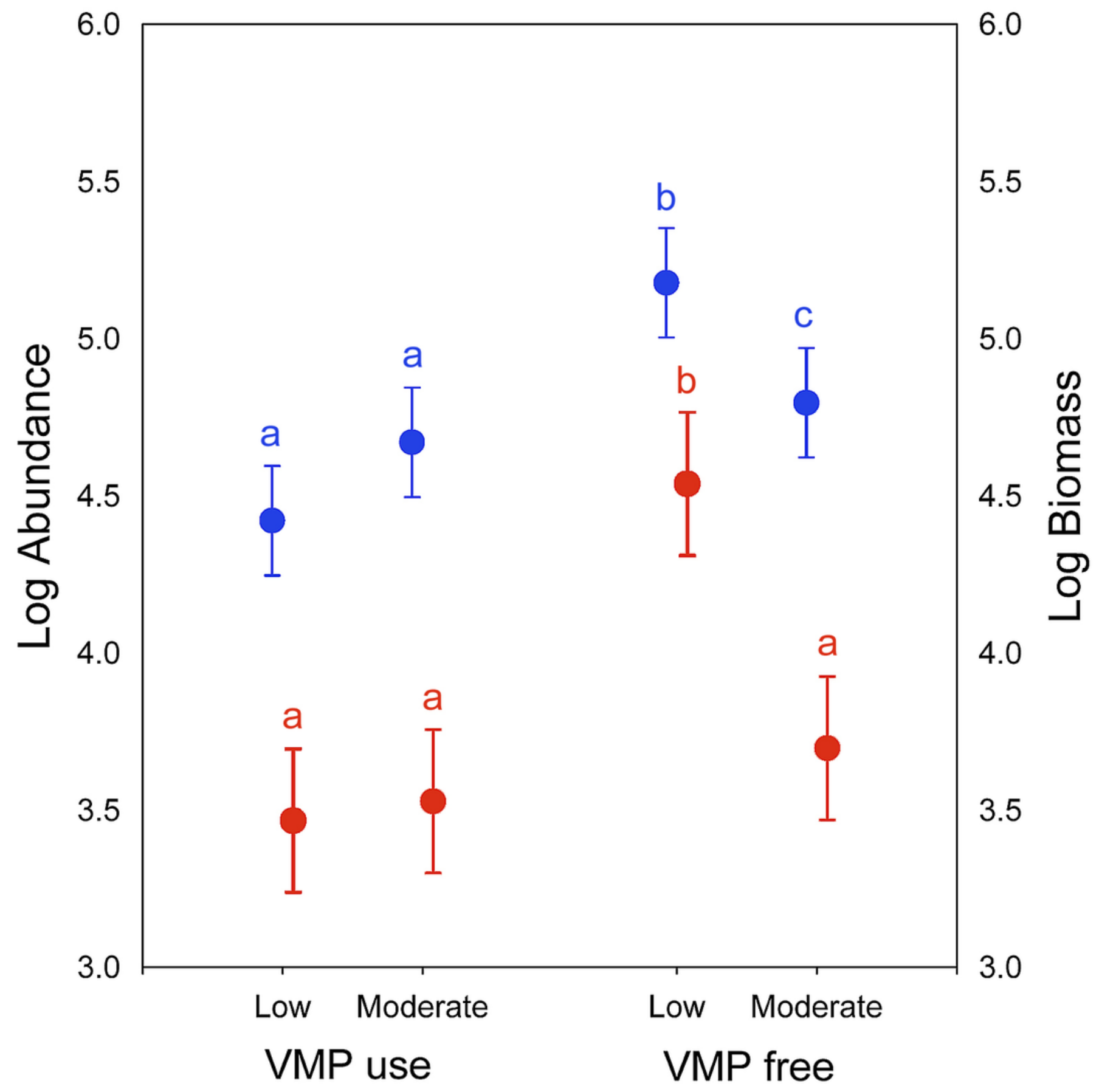




\section{Figure 3}

Beta diversity of dung beetles between sites.

Multiple community similarity using Non-Metric Multidimensional Scaling (NMDS) ordination:

A) Generalised Sørensen index $\left(C_{o N}\right)$ : Average proportion of shared species in each assemblage based on the incidence data; B) Horn entropy index $\left(C_{1 N}\right)$ : proportion of shared species in an assemblage based on abundance data; and C) Morisita-Horn index $\left(C_{2 N}\right)$ : proportion of shared species in an assemblage based on abundance data of the most abundant (dominant) species. A two dimensional ordination was selected. Each point corresponds to a treatment replication. Squares correspond to moderate grazing areas and triangles to low grazing sites. Sites where VMPs are used are shown in red, whereas sites without any use of VMPs are in blue. 


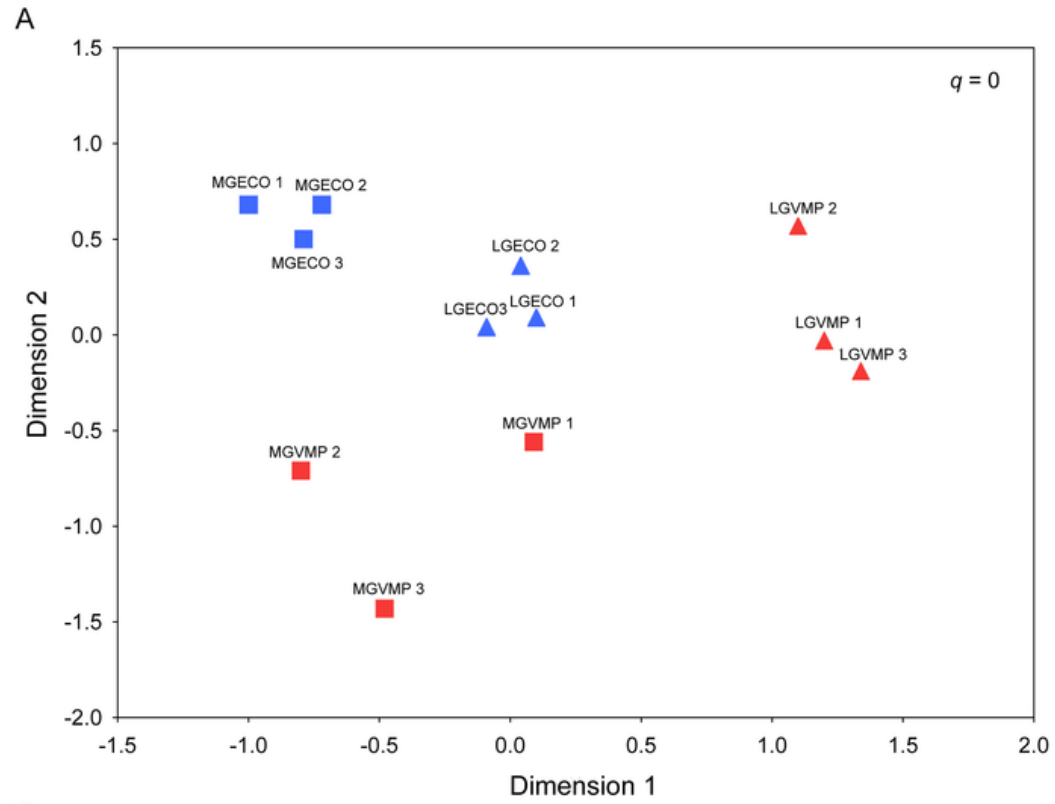

B

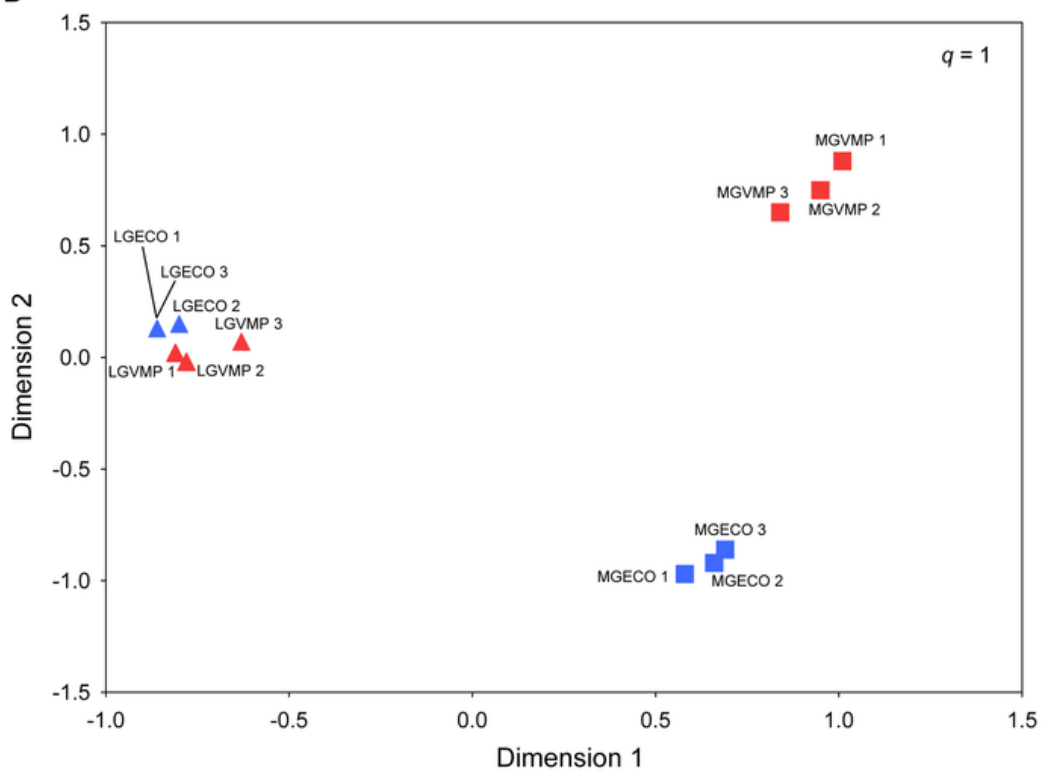

C

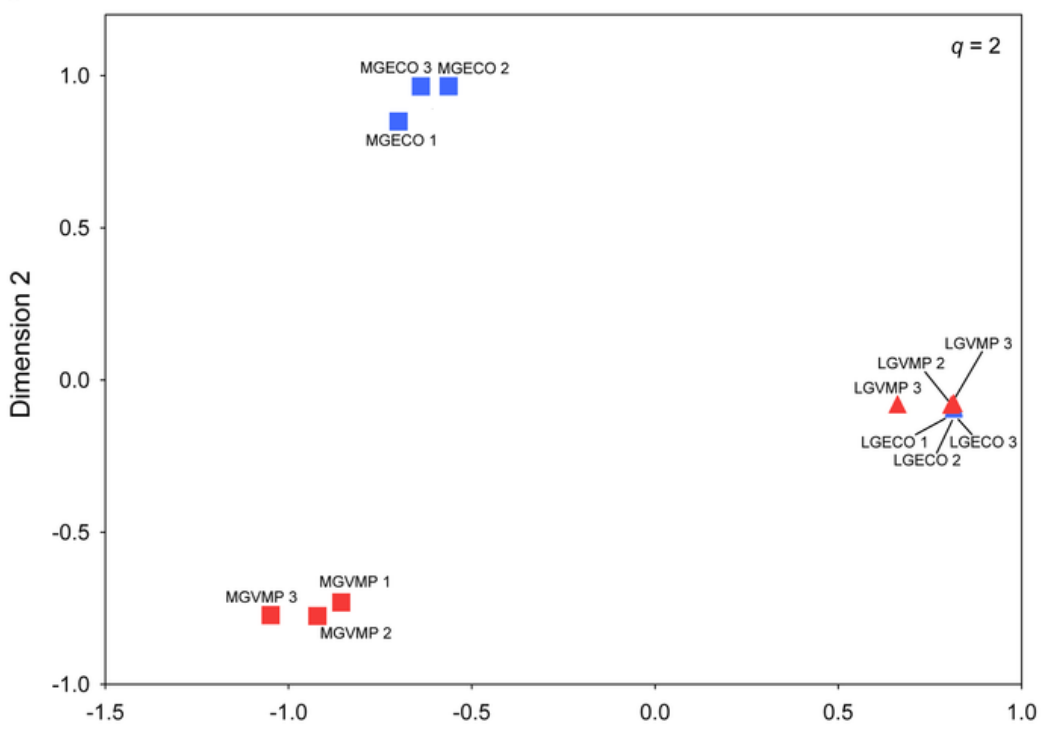

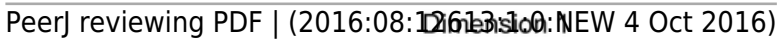




\section{Table $\mathbf{1}$ (on next page)}

Dung beetle indicators of different livestock grazing management techniques.

Numbers represent statistically significant IndVal values $(P<0.05)$. LG: low grazing; MG: moderate grazing; ECO: VMP free; VMP: VMP use. 
1

Family Indicator species

Aphodiidae

Aphodius fimetarius (Linnaeus, 1758)

Chilothorax conspurcatus (Linnaeus, 1758)

Melinopterus consputus (Creutzer, 1799)

Bodilopsis rufa (Moll, 1782)

Calamosternus granarius (Linnaeus, 1767)

Labarrus lividus (Olivier, 1789)

Melinopterus prodromus (Brahm, 1790)

Acanthobodilus immundus (Creutzer, 1799)

Nimbus johnsoni (Baraud, 1976)

Acrossus luridus (Fabricius, 1775)

Aphodius foetidus (Herbst, 1783)

Loraphodius suarius (Faldermann, 1836)

Otophorus haemorroidalis (Linnaeus, 1758)

Sigorus porcus (Fabricius, 1792)

\section{LG MG ECO VMP}

90.5

93.7

95.9

97.3

97.4

83.3

76.4

99.7

76.1

79.4

96

83.3

90.4

Scarabaeidae

Onthophagus fracticornis (Preyssler, 1790)

84.3

Onthophagus ruficapillus Brullé, 1832

80.6

Onthophagus taurus (Schreber, 1759)

$91.3 \quad 89.8$

Onthophagus coenobita (Herbst, 1783)

91.3

Onthophagus opacicollis Reitter, 1892 
Bubas bison (Linnaeus, 1767)
Copris lunaris (Linnaeus, 1758)

Geotrupidae

Sericotrupes niger (Marsham, 1802)

97.2

90.5

2 


\section{Table 2 (on next page)}

Species compositional similitude among dung beetle assemblages.

The $q$ levels $(0,1$ and 2$)$ indicate the value by which multiple community similarity matrices $\left(C_{q 3}\right)$ were calculated. $\mathrm{GI}=$ the grazing intensity factor; VMP = the VMP-use factor. $P$ values are calculated using the Bonferroni correction. 


\begin{tabular}{|c|c|c|c|c|c|c|}
\hline Parameter & Source & $\mathrm{df}$ & $S S$ & $M S$ & Pseudo-F & $P$ \\
\hline & GI & 1 & 4960.6 & 4960.6 & 1.0089 & 0.003 \\
\hline & VMP & 1 & 4961.3 & 4961.3 & 1.009 & 0.003 \\
\hline \multirow[t]{5}{*}{$q=0$} & GI x VMP & 1 & 4949.2 & 4949.2 & 1.0066 & 0.027 \\
\hline & Residuals & 8 & 39336 & 4916.9 & & \\
\hline & Total & 11 & 54207 & & & \\
\hline & GI & 1 & 5118.3 & 5118.3 & 1.043 & 0.003 \\
\hline & VMP & 1 & 4966.5 & 4966.5 & 1.0121 & 0.225 \\
\hline \multirow[t]{5}{*}{$q=1$} & GI x VMP & 1 & 4977.3 & 4977.3 & 1.0143 & 0.156 \\
\hline & Residuals & 8 & 39259 & 4907.4 & & \\
\hline & Total & 11 & 54321 & & & \\
\hline & GI & 1 & 5234.2 & 5234.2 & 1.0667 & 0.003 \\
\hline & VMP & 1 & 5000.4 & 5000.4 & 1.0191 & 0.213 \\
\hline \multirow[t]{3}{*}{$q=2$} & GI x VMP & 1 & 4984.2 & 4984.2 & 1.0158 & 0.258 \\
\hline & Residuals & 8 & 39255 & 4906.9 & & \\
\hline & Total & 11 & 54474 & & & \\
\hline
\end{tabular}

